\title{
One-Pot Synthesis of Trisubstituted Conjugated Dienes via Sequential Suzuki-Miyaura Cross-Coupling with Alkenyl- and Alkyltrifluoroborates
}

\author{
Gary A. Molandera, ${ }^{*}$ and Yasuo Yokoyama ${ }^{a, b}$ \\ a Roy and Diana Vagelos Laboratories, Department of Chemistry, University of Pennsylvania, Philadelphia, \\ Pennsylvania 19104-6323 \\ b Department of Chemistry, Faculty of Science and Technology, Sophia University, 7-1 Kioicho, Chiyoda- \\ ku, Tokyo 102-8554, Japan
}

\begin{abstract}
The sequential, stereoselective disubstitution of 1,1-dibromoalkenes using a variety of alkenyltrifluoroborates followed by alkyltrifluoroborates in the presence of $\mathrm{Pd}\left(\mathrm{PPh}_{3}\right) 4$ is described. This synthetic method proceeds smoothly in one pot under mild reaction conditions to provide the corresponding trisubstituted, conjugated dienes in excellent yield. Moreover, the method is operationally very simple, because the organotrifluoroborates are stable in air, and the byproducts are innocuous inorganic salts.
\end{abstract}

\section{Keywords}

Trisubstituted alkenes; alkenyltrifluoroborate; alkyltrifluoroborate; Suzuki coupling

\section{Introduction}

The regio- and stereoselective synthesis of trisubstituted alkenes remains one of the more troublesome problems in organic synthesis. Although this structural unit appears in a variety of natural products and advanced materials, general, stereoselective approaches to compounds of this class remain elusive.

Depending on the array of functionality and types of organic groups desired to be proximal to the alkene, a number of diverse approaches to trisubstituted alkenes can be chosen. ${ }^{1}$ The scope and limitations of many of the most popular and useful protocols (e.g., Wittig and related approaches, as well as hydrometalation and carbometalation procedures) have been elegantly pointed out by Negishi et al. ${ }^{2}$

One very attractive approach to stereodefined trisubstituted alkenes is the stepwise double substitution of readily available 1,1 -dihaloalkenes ${ }^{3}$ by organometallic reagents in the presence of a transition metal catalyst. Prominent among such approaches are Tamao, Stille, Negishi, and Suzuki-Miyaura couplings. Among the earliest examples of this reactivity pattern, in 1987 Minato and Tamao revealed that organomagnesiums and organozincs could be partnered with 1,1-dichloroalkenes to afford several trisubstituted alkenes via two-pot diarylation and dialkylation sequences. ${ }^{4}$ In 1999 , Shen and Wang applied the Stille coupling 5 to the

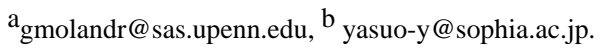


disubstitution of 1,1-dibromo-1-alkenes. ${ }^{6}$ In this case, trisubstituted alkenes could be synthesized through stereoselective arylation/alkenylation, arylation/alkylation, and alkenylation/arylation sequences in moderate to good yields in two-pot processes. Additionally, access to several trisubstituted alkenes via one-pot alkylation and arylation protocols were reported.

Most recently, Negishi and co-workers reported that palladium complexes, such as $\mathrm{Cl}_{2} \mathrm{Pd}$ (DPEphos) or $\mathrm{Pd}\left(\mathrm{PPh}_{3}\right)_{4}$, successfully catalyzed various disubstitutions of 1,1-dihaloalkenes. Stereoselective arylation/alkylation and alkynylation/alkylation sequences were accomplished with organozincs in the presence of the foregoing catalysts, and the desired compounds were obtained in good to excellent yield. ${ }^{7}$ This group also reported that stereoinverted alkylations may occur in the second step when utilizing certain dihalogenated compounds. ${ }^{2}$

Soderquist and co-workers investigated the double intermolecular Suzuki-Miyaura crosscoupling reaction (methylation/methylation) of 1,1-dibromo-1-alkenes, ${ }^{8}$ and also applied a related protocol to the formation of various cyclic compounds. ${ }^{9}$ In the latter scenario, $\alpha, \omega$ diborylalkanes synthesized from the corresponding diene and 9-BBN reacted with 1,1dibromoalkenes to give the desired compounds.

Most of these synthetic methods were very effective for the synthesis of the desired trisubstituted alkenes, but some substrates were transformed to the desired compound in low yield in a two-pot procedure wherein the intermediate alkenyl halide was isolated. Furthermore, the organozinc and some of the organoboron compounds used in such transformations are impossible to store in the air and are sometimes difficult to synthesize. The organostannanes used in Stille coupling reactions generally suffer from toxicity and environmental concerns, as well as purity issues of the final product associated with tin-containing by-products. Thus, the development of more effective, convenient, and environmentally sound reagents for a sequential coupling process was strongly desired.

The application of air-stable, storable potassium organotrifluoroborates in one-pot crosscoupling reactions with 1,1-dibromoalkenes was recognized as one potential solution to some of the drawbacks associated with other procedures. The advantages of this protocol would be derived in part from the unique nature of the coupling reagents. Organotrifluoroborates are inherently more stable to air and moisture than the corresponding organozincs, organomagnesiums, and organoboron reagents. ${ }^{10}$ Various organotrifluoroborates can be synthesized easily and at low cost, ${ }^{10}$ and many organotrifluoroborates are now commercially available. Finally, the waste materials of these reactions are non-toxic inorganic salts, which can be easily removed from the reaction system.

In previous investigations, the scope of cross-coupling reactions of various organotrifluoroborates with functionalized alkenyl halides has been studied. ${ }^{11}$ In these explorations, palladium complexes promoted the smooth Suzuki-Miyaura cross-coupling reaction of organotrifluoroborates, and the corresponding compounds were obtained stereoselectively in good to excellent yields (eq 1).

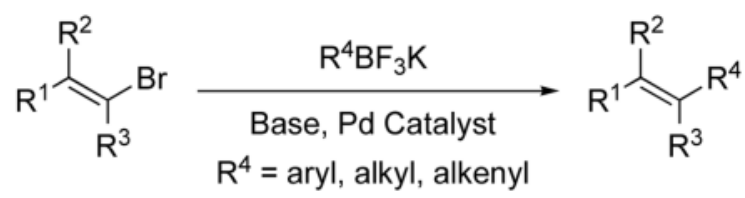

(1).

In fact, Kabalka has recently described the synthesis of trisubsituted, conjugated enediynes via palladium-catalyzed cross-coupling of two equivalents of alkynyltrifluoroborates with 1,1- 
dibromoalkenes (eq 2). ${ }^{12}$ Thus, it seemed likely that other organotrifluoroborates could be coupled sequentially to 1,1-dibromides, providing access to trisubstituted alkenes. As a starting point for these studies, the serial coupling of alkenyltrifluoroborates followed by alkyltrifluoroborates was explored (eq 3).

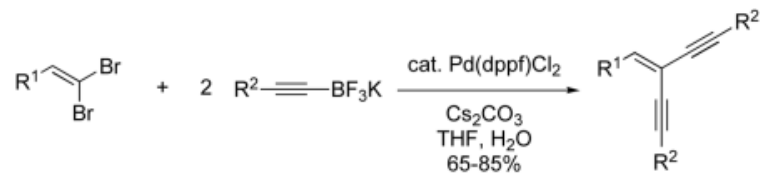

(2).

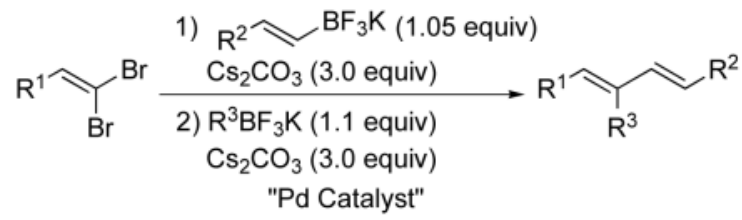

(3).

Herein the successful results of these studies are reported, wherein a stereoselective, one-pot process has been developed utilizing $\mathrm{Pd}\left(\mathrm{PPh}_{3}\right)_{4}$ as a catalyst. The protocol developed is operationally simple and easy to carry out, and moreover, the target compounds are obtained stereoselectively in excellent yield under mild reaction conditions.

\section{Results and Discussion}

To begin, 1,1-dibromo-2-cyclohexylethene (1), potassium $(E)$-1-hex-5-enoic acid trifluoroborate, methyl ester (2), and potassium 2-phenylethyl trifluoroborate (3) were chosen as model substrates. Conditions for the one-pot synthesis of the trisubstituted diene derivative using Suzuki-Miyaura cross-coupling were sought, and the process was optimized. Pertinent results from these studies are summarized in Table 1.

The geminal dibromide 1 reacted with 1.1 equiv of $\mathbf{2}$ in the presence of $7 \mathrm{~mol} \%$ of $\mathrm{Pd}$ $\left(\mathrm{PPh}_{3}\right)_{4}$ and three equivalents of $\mathrm{Cs}_{2} \mathrm{CO}_{3}$ at $80{ }^{\circ} \mathrm{C}$ for $1.25 \mathrm{~h}$. Subsequently, alkyl trifluoroborate 3 (1.1 equiv) and an aqueous solution of $\mathrm{Cs}_{2} \mathrm{CO}_{3}$ (3.0 equiv) were added to afford the target compound 4 with complete stereoselectivity in $85 \%$ yield (entry 1). No other catalysts were explored extensively, and, on the scale the reactions performed, $7 \mathrm{~mol} \%$ catalyst loading proved optimum. This protocol was high-yielding, but an undesired by-product was formed that originated from coupling of $\mathbf{1}$ with two equivalents of $\mathbf{2}$ [i.e., a bis(alkenyl) coupled product] in about $10 \%$ yield. Further experimentation determined that the first step of the twostep process could be carried out at lower temperature, but the second reaction required a higher temperature to proceed to completion. For example, when the entire process was carried out at $60{ }^{\circ} \mathrm{C}$, the sequentially coupled compound was not obtained at all, although formation of the initial monoalkenyl coupled compound was complete (entry 2). To rectify this problem, the first coupling reaction was carried out at $60^{\circ} \mathrm{C}$, while the second coupling reaction was conducted at $80^{\circ} \mathrm{C}$. Under these conditions the target compound was obtained in good yield (entry 3). An attempt was made to reduce the excess of alkenyl trifluoroborate utilized in the initial reaction. However, when only one equivalent of alkenyl trifluoroborate $\mathbf{2}$ was used as a substrate, the first step required a relatively long time to go to completion (entry 4). Finally, it was found possible to reduce the formation of the bis(alkenyl) coupled by-product and to obtain a high yield of the target compound by using just a slight excess (1.05 equiv) of $\mathbf{2}$, and in this case the desired diene was obtained in $89 \%$ yield (entry 5 ). Under these conditions, the yield of the bis(alkenyl) coupled byproduct was reduced to levels $\leq 5 \%$. Efforts were made to improve the process further by examining different palladium catalysts and bases. However, Pd 
$\left(\mathrm{PPh}_{3}\right)_{4}$ was determined to be the best catalyst for this reaction system in terms of yield and cost, and $\mathrm{Cs}_{2} \mathrm{CO}_{3}$ remained the most effective among the diverse bases examined. ${ }^{11 \mathrm{~b}}$

With a suitable protocol in hand the scope of this synthetic method was examined by first using various alkyltrifluoroborates (Table 2). When alkyltrifluoroborates bearing ester substituents [trimethylacetyloxy ( $\mathrm{PivO}$ ) and benzoyloxy (BzO) groups] were used as substrates in the second coupling reaction, the target compounds were accessed in excellent yields (entries 1 and 2). Ester hydrolysis products were not detected, even though aqueous basic conditions were employed. ${ }^{11 \mathrm{~b}}$ A cyano-substituted alkyltrifluoroborate could also be transformed to the desired product very effectively (entry 3). The 5,7-dienyl carboxylate incorporating a ketone unit could be synthesized easily employing 11 (entry 4). When thioether $\mathbf{1 3}$ was used as a substrate, the second reaction proceeded smoothly to give the target compound in good yield (entry 5). In all cases, only one stereoisomer of the target compound was obtained, and the sense of this diastereoselection was determined by nOe studies (see Figure 1 below). The experiments completed in the first phase of our studies confirmed that diversely functionalized alkyl trifluoroborates were effective substrates for the reaction employing the reaction conditions developed in the model reaction, and this prompted us to explore the scope and limitations in greater detail.

Interestingly, in contrast to the functionalized alkyl trifluoroborates described above, organotrifluoroborates such as potassium methyl trifluoroborate (15), potassium ethyl trifluoroborate (17), and potassium 4-pentenyl trifluoroborate (19), proved to be more reluctant coupling partners (Table 3 ). These substrates could not be transformed to the desired products at all when the reactions were carried out under the same reaction conditions utilized for substrates in Table 2. Consequently, we refined the reaction conditions for the second coupling step for these organotrifluoroborates. A series of investigations guided us to a solution to this problem. Thus, at a higher reaction temperature $\left(90^{\circ} \mathrm{C}\right)$, with the addition of $\mathrm{PdCl}_{2}(\mathrm{dppf})$ . $\mathrm{CH}_{2} \mathrm{Cl}_{2}$ complex (used previously in related coupling processes), $11 \mathrm{~g}$ and by using solid $\mathrm{Cs}_{2} \mathrm{CO}_{3}$ (as opposed to an aqueous solution), effective methylation, ethylation, and pentenylation of the monobromodiene initially formed in situ could be achieved. The results of these modified conditions are displayed in Table 3 . When $\mathbf{1 5}$ was used as a substrate for the second coupling reaction, the desired product was obtained in good yield (entry 1).

Furthermore, ethyl trifluoroborate and 4-pentenyl trifluoroborate were also effective substrates in this synthetic reaction. Compounds $\mathbf{1 7}$ and $\mathbf{1 9}$ could be transformed to the corresponding diene derivatives in good yields (entries 2 and 3). Of particular note, this transformation exhibits significant advantages over many other disubstitution reactions of 1,1-dihaloalkenes in the sense that methylation in the second step was highly successful, affording the desired compound in good yield. High yielding methylations of this type have proven to be challenging in previously reported protocols, $2,7 \mathrm{a}, \mathrm{b}, 13$ and a general one-pot, two-stage conversion of the type described herein appears to be extremely rare. $6,7 \mathrm{~b}, 13$ In previous attempts at such transformations, a mismatch occurs between the two different organometallic partners and the catalyst complexes (specifically the ligand array) required to support their successive in situ coupling to the halide. $7 \mathrm{~b}$

The results depicted in Table 2 compared to those in Table 3 appear to demonstrate that the reactivity of the alkyl trifluoroborate is somehow associated with functionality incorporated within the substrate itself. Whether the small, aliphatic trifluoroborate salts are simply less soluble than more elaborate reagents or whether these polar groups in conjunction with the trifluoroborate somehow change the nature of the palladium catalyst is unknown. However, it is clear that polar functional groups enhance the reactivity of the organotrifluoroborates, indicating that reaction conditions may have to be customized to some extent depending on the nature of the organic moiety in the reagent. 
In addition to being able to use a variety of alkyl trifluoroborates in the second step of the sequential one-pot process, diverse alkenyl trifluoroborates could be used as starting materials for the first step of the synthesis. The results of these investigations are summarized in Table 4. Thus, an alkenyl trifluoroborate possessing a cyano substituent (21) reacted with dibromide 1 to give the corresponding monobromide under mild reaction conditions, and this intermediate could be transformed in situ to the desired compound in the presence of $\mathbf{5}$ or $\mathbf{1 1}$ in excellent yields (entries 1 and 2). Potassium (E)-5-chloro-1-pent-1-enyl trifluoroborate $\mathbf{2 4}$ was also used as a substrate. The target compounds were obtained in excellent yields with retention of the chloride (entries 3 and 4). Some alkenyl trifluoroborates incorporating simple hydrocarbon chains reacted with dibromide $\mathbf{1}$ under the optimized reaction conditions. When $\mathbf{2 7}$ was treated with dibromide $\mathbf{1}$, the desired monobromide was very effectively generated in situ, and this compound reacted with organotrifluoroborates $\mathbf{5}$ or $\mathbf{1 1}$ to give the corresponding dienes in excellent yields (entries 5 and 6). When $\mathbf{3 0}$ was used as a substrate under the standard conditions, the first coupling reaction took a longer period of time, and many unidentified byproducts were obtained. Given our experience with other recalcitrant coupling partners, we performed this reaction using compound 30 at a higher temperature $\left(80^{\circ} \mathrm{C}\right)$. As shown in entries $7-9$ of Table 4, when the first step of these reactions was carried out at $80^{\circ} \mathrm{C}$ for $5.0 \mathrm{~h}$ followed by a second reaction with alkyl trifluoroborates $\mathbf{5 , 1 1}$, or $\mathbf{3}$, the desired compounds were isolated in excellent yields. Overall, the synthetic method developed showed high compatibility with all manner of organotrifluoroborate coupling partners.

Owing to the reports of Negishi concerning a stereoinversion process that can occur during related trisubstituted alkene syntheses, ${ }^{13}$ there was some concern about the sense of diastereoselection in these processes. These concerns were allayed upon finding an $11.8 \% \mathrm{NOE}$ enhancement between two vinylic protons in $\mathbf{2 2}$ to establish the $E, E$ stereochemistry by a technique that has been utilized previously for stereochemical confirmation in related systems (Figure 1). 2,13

In the final phase of our studies, the diversity allowed in the last of the three components was explored. Thus, several different 1,1-dibromoalkenes were examined for their effectiveness in the reaction. For example, 1,1-dibromonon-1-ene $\mathbf{3 4}$ was used as a substrate, and the target compound was obtained in good yield (eq 4). 1,1-Dibromo-4-phenyl-but-1-ene $\mathbf{3 6}$ also reacted with 2 and then 5 to give the corresponding compound in good yield (eq 5). When these acyclic dibromides possessing a methylene group at the allylic position were employed as starting materials, a mixture of stereoisomeric products was formed, with the $E, E$-isomer still predominating $(E, E / E, Z=>92 /<8)$. Thus the sterically demanding cyclohexyl group of dihalide 1 utilized in Tables 1-4 more effectively controlled the stereoselectivities of the initial coupling reaction than unbranched aliphatic groups. (S)-(+)-1,1-Dibromo-4,8-dimethyl-1,7-nonadiene 38 derived from $(S)-(-)$-citronellal sequentially reacted with organotrifluoroborates $\mathbf{2}$ and then 5 to form the corresponding chiral product in good yield (eq 6).Finally, the $\alpha, \beta, \gamma, \delta$-unsaturated dibromide 40, which was prepared from $(S)$-(-)-perillaldehyde, was also transformed to the desired product with complete stereochemical control (eq 7). In this way the method was extended to conjugated 1,1-dibromides, indicating that more highly conjugated systems are also very effective substrates for this reaction. 


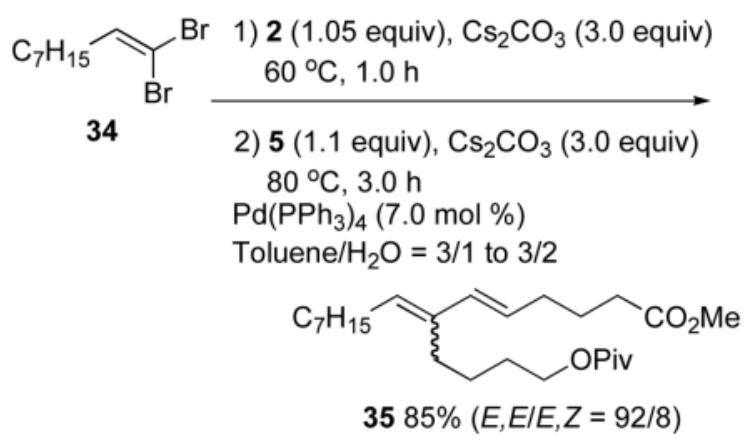

(4).

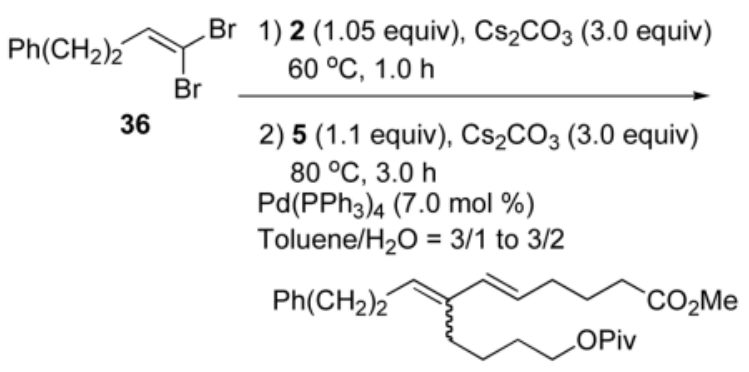

$3787 \%(E, E / E, Z=94 / 6)$

(5).

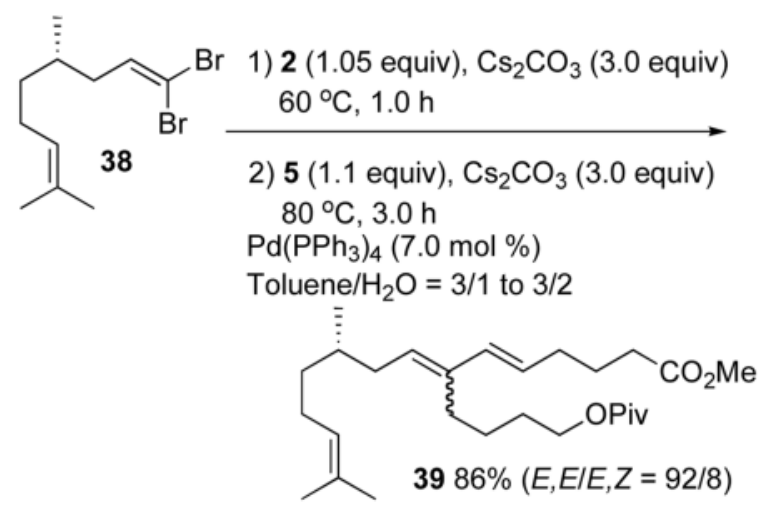

(6).

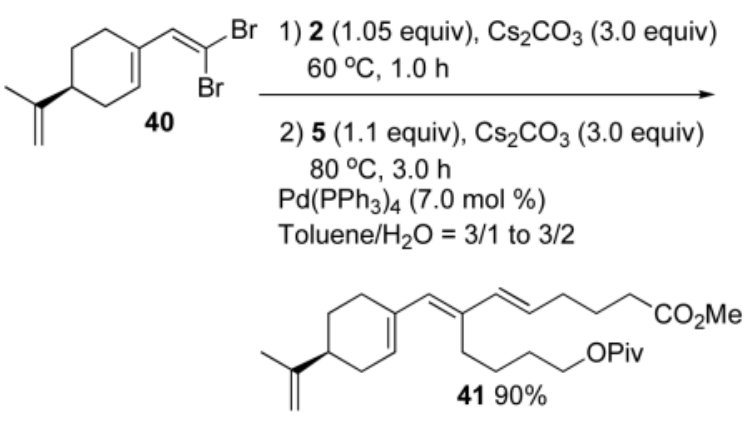

(7). 


\section{Conclusion}

In summary, we have developed an effective and convenient one-pot synthesis of stereodefined, trisubstituted, conjugated dienes using alkenyl- and alkyltrifluoroborates through the sequential disubstitution of 1,1-dibromoalkenes. This synthetic method proceeded smoothly to provide the desired products in excellent yields. At this point in time, the protocol developed appears general for all three components of the reaction. Thus, a variety of functionalized alkenyl trifluoroborates have been employed, although diverse stereochemistries and substitution patterns remain to be examined. Perhaps most importantly, conditions are reported for primary alkyl trifluoroborates ranging from simple methyl and ethyl derivatives to more highly functionalized alkyl trifluoroborates. Finally, a diverse group of 1,1-dibromoalkenes takes part in the reaction, including conjugated 1,1-dibromoalkenes. Stereoselectivities are generally quite high, although dependent upon the steric properties of the geminal dihalide. In most cases, a single catalyst precursor can be employed to carry out the transformation. Curiously, $\mathrm{Pd}\left(\mathrm{PPh}_{3}\right)_{4}$ has proven to be the most effective precatalyst, in spite of the fact that this particular system is not normally used for alkyl cross-coupling because of its inability to suppress competitive $\beta$-hydride elimination. Finally, utilizing this protocol the use of superstoichiometric thallium bases are avoided that often plague the construction of trisubstituted dienes using other boron reagents. ${ }^{14}$ Sequential protocols for the one-pot synthesis of complementary classes of trisubstituted alkenes involving diverse trifluoroborates in both reaction order combinations are currently in progress.

\section{Experimental Section}

\section{General Procedure for the Cross-coupling Reaction of 1,1-Dibromoalkenes with Potassium Alkenyltrifluoroborates and Alkyltrifluoroborates. Synthesis of $(E, E)-8-C y c l o h e x y l-7-(4-$ trimethylacetoxybutyl)-octa-5,7-dienoic Acid, Methyl Ester (6)}

1,1'-Dibromo-2-cyclohexylethene (268 $\mathrm{mg}, 1.0 \mathrm{mmol}$ ) was added slowly to a toluene- $\mathrm{H}_{2} \mathrm{O}$ solution $(3.0 \mathrm{~mL}+1.0 \mathrm{~mL})$ of $\mathrm{Cs}_{2} \mathrm{CO}_{3}(977 \mathrm{mg}, 3 \mathrm{mmol})$, potassium $(E)$-1-hex-5-enoic acid trifluoroborate, methyl ester $(245 \mathrm{mg}, 1.05 \mathrm{mmol})$, and $\mathrm{Pd}\left(\mathrm{PPh}_{3}\right)_{4}(80 \mathrm{mg}, 0.07 \mathrm{mmol})$ at $60^{\circ}$ $\mathrm{C}$ under $\mathrm{N}_{2}$. After stirring for $2.0 \mathrm{~h}$, potassium 1-trimethylacetyloxybutyl trifluoroborate (291 $\mathrm{mg}, 1.1 \mathrm{mmol})$ and an aqueous solution of $\mathrm{Cs}_{2} \mathrm{CO}_{3}(3.0 \mathrm{M}, 1 \mathrm{~mL})$ were added to the reaction mixture. After stirring for $2 \mathrm{~h}$ at $80{ }^{\circ} \mathrm{C}$, a mixture of silica gel and $\mathrm{Na}_{2} \mathrm{SO}_{4}(1 / 1,13 \mathrm{~g})$ was added to the mother liquor and this mixture was passed through a short column of silica gel ( $7.0 \mathrm{~g}$, hexane) and eluted with $\mathrm{Et}_{2} \mathrm{O}(120 \mathrm{~mL})$. Concentration of this eluate followed by column chromatographic purification $\left(\mathrm{SiO}_{2}\right.$, hexane/Et $\left.\mathrm{H}_{2} \mathrm{O}=20 / 1\right)$ afforded $\mathbf{6}(348 \mathrm{mg}, 89 \%)$ as a colorless oil. ${ }^{1} \mathrm{H}$ NMR $\left(500 \mathrm{MHz}, \mathrm{CDCl}_{3}\right), \delta 5.91(\mathrm{~d}, J=15.9 \mathrm{~Hz}, 1 \mathrm{H}), 5.49(\mathrm{dt}, J=15.9,6.6$ $\mathrm{Hz}, 1 \mathrm{H}), 5.19(\mathrm{~d}, J=9.8 \mathrm{~Hz}, 1 \mathrm{H}), 4.08(\mathrm{t}, J=6.3 \mathrm{~Hz}, 2 \mathrm{H}), 3.66(\mathrm{~s}, 3 \mathrm{H}), 2.31(\mathrm{t}, J=8.0 \mathrm{~Hz}$, $2 \mathrm{H}), 2.23-2.20(\mathrm{~m}, 3 \mathrm{H}), 2.11(\mathrm{q}, J=7.6 \mathrm{~Hz}, 2 \mathrm{H}), 1.74-1.58(\mathrm{~m}, 10 \mathrm{H}), 1.47-1.43(\mathrm{~m}, 2 \mathrm{H})$, $1.29-1.26(\mathrm{~m}, 2 \mathrm{H}), 1.19(\mathrm{~s}, 9 \mathrm{H}), 1.18-1.05(\mathrm{~m}, 2 \mathrm{H}) ;{ }^{13} \mathrm{C} \mathrm{NMR}\left(125.8 \mathrm{MHz}, \mathrm{CDCl}_{3}\right) \delta 178.6$, 174.0, 137.5, 135.5, 134.7, 125.8, 64.2, 51.4, 38.7, 37.2, 33.5, 33.3 (2C), 32.3, 28.9, 27.2 (3C), 26.7, 26.0, 25.9 (2C), 25.8, 24.8. HRMS (ESI): $m / z$ calcd. For $\mathrm{C}_{24} \mathrm{H}_{40} \mathrm{NaO}_{4}\left(\mathrm{M}^{+}+\mathrm{Na}\right)$ 415.2824, found 415.2823. IR (neat): 2926, 2851, 1732, 1448, 1284, 1155, 966, $771 \mathrm{~cm}^{-1}$.

\section{Supplementary Material}

Refer to Web version on PubMed Central for supplementary material.

\section{Acknowledgements}

We acknowledge the National Institutes of Health (GM35249), Amgen, and Merck Research Laboratories for their generous support of this work. Additionally, we thank Johnson-Matthey for supplying the catalysts used in this research. Finally, we acknowledge Ms. Luciana Felix for performing some preliminary studies in this area, and Dr. Rakesh Kohli for the HRMS data. 


\section{References and Notes}

1. (a) Itami K, Mineno M, Muraoka N, Yoshida J. J Am Chem Soc 2004;126:11778-11779. [PubMed: 15382897] (b) Itami K, Tonogaki K, Ohashi Y, Yoshida J. Org Lett 2004;6:4093-4096. [PubMed: 15496107] (c) Tonogaki K, Soga K, Itami K, Yoshida J. Synlett 2005:1802-1904. (d) Chen YK, Walsh PJ. J Am Chem Soc 2004;126:3702-3703. [PubMed: 15038709] (e) Li H, Walsh PJ. J Am Chem Soc 2005;127:8355-8361. [PubMed: 15941269] (e) Xu C, Negishi E. Tetrahedron Lett 1999;40:431-434. (f) Roush WR, Koyama K, Curtin ML, Moriarty KJ. J Am Chem Soc 1996;118:7502-7512. (g) Satoh M, Miyaura N, Suzuki A. Chem Lett 1986:1329-1332. (h) Brown HC, Bhat NG. J Org Chem 1988;53:6009-6013. (i) Martin SF, Daniel D, Cherney RJ, Liras S. J Org Chem 1992;57:2523-2525. (j) Denmark SE, Amburgey J. J Am Chem Soc 1993;115:10386-10387. (k) Chatterjee AK, Grubbs RH. Org Lett 1999;1:1751-1753. [PubMed: 10836036] (1) Trost BM, Shen HC, Pinkerton AB. Chem Eur J 2002;8:2341-2349.

2. Zeng X, Qian M, Hu Q, Negishi E. Angew Chem, Int Ed 2004;43:2259-2263.

3. (a) Ramirez F, Desai NB, McKelvie N. J Am Chem Soc 1962;84:1745-1747. (b) Corey EJ, Fuchs PL. Tetrahedron Lett 1972:3769-3772. (c) Fisher RP, On HP, Snow JT, Zweifel G. Synthesis 1982:127129.

4. Minato A, Suzuki K. J Am Chem Soc 1987;109:1257-1258.

5. Some reviews: (a) Nicolaou KC, Bulger PG, Sarlah D. Angew Chem, Int Ed 2005;44:4442-4489. (b) Li C-J. Chem Rev 2005;105:3095-3165. [PubMed: 16092827] (c) Echavarren AM. Angew Chem, Int Ed 2005;44:3962-3965.

6. Shen W, Wang L. J Org Chem 1999;64:8873-8879. [PubMed: 11674792]

7. (a) Shi J-C, Zeng X, Negishi E. Org Lett 2003;5:1825-1828. [PubMed: 12762662] (b) Shi J-C, Negishi E. J Organomet Chem 2003;687:518-524. Review: (c) Negishi E, Hu Q, Huang Z, Qian M, Wang G. Aldrichimica Acta 2005;38:72-38.

8. Soderquist JA, Bantiago B. Tetrahedron Lett 1990;31:5541-5542.

9. Soderquist JA, León G, Colberg JC, Martinez I. Tetrahedron Lett 1995;36:3119-3122.

10. Molander GA, Figueroa R. Aldrichimica Acta 2005;38:49-56.

11. (a) Molander GA, Petrillo DE, Landzberg NR, Rohanna JC, Biolatto B. Synlett 2005:1763-1766. (b) Molander GA, Felix LA. J Org Chem 2005;70:3950-3956. [PubMed: 15876083] (c) Molander GA, Dehmel F. J Am Chem Soc 2004;126:10313-10318. [PubMed: 15315445] (d) Molander GA, Ribagorda M. J Am Chem Soc 2003;125:11148-11149. [PubMed: 16220907] (e) Molander GA, Yun CS, Ribagorda M, Biolatto B. J Org Chem 2003;68:5534-5539. [PubMed: 12839444] (f) Molander GA, Biolatto B. J Org Chem 2003;68:4302-4314. [PubMed: 12762730] (g) Molander GA, Bernardi CR. J Org Chem 2002;67:8424-8429. [PubMed: 12444620] (h) Molander GA, Katona BW, Machrouhi F. J Org Chem 2002;67:8416-8423. [PubMed: 12444619] (i) Molander GA, Biolatto B. Org Lett 2002;4:1867-1870. [PubMed: 12027634] (j) Molander GA, Rivero MR. Org Lett 2002;4:107-109. [PubMed: 11772102] (k) Molander GA, Ito T. Org Lett 2001;3:393-396. [PubMed: 11428022]

12. Kabalka GW, Dong G, Venkataiah B. Tetrahedron Lett 2005;46:763-765.

13. Zeng X, Hu Q, Qian M, Negishi E. J Am Chem Soc 2003;125:13636-13637. [PubMed: 14599182]

14. (a) Scheidt KA, Bannister TD, Tasaka A, Wendt MD, Savall BM, Fegley GJ, Roush WR. J Am Chem Soc 2002;124:6981-6990. [PubMed: 12059221] (b) Kobayashi S, Mori K, Wakabayashi T, Yasuda S, Hanada K. J Org Chem 2001;66:5580-5584. [PubMed: 11485486] (c) Shimizu T, Satoh T, Murakoshi K, Sodeoka M. Org Lett 2005;7:5573-5576. [PubMed: 16320994] 


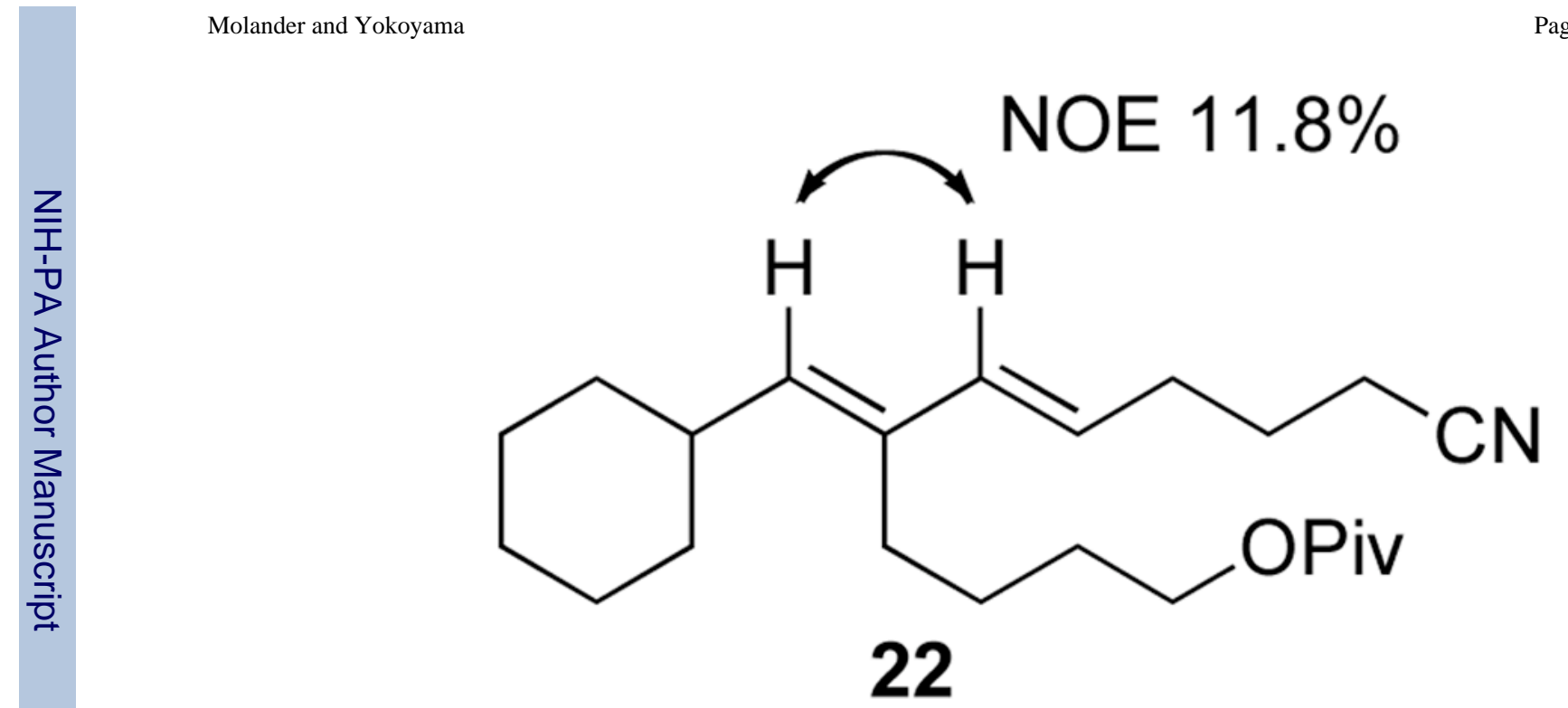

Figure 1.

Determination of stereochemistry by NOE. 


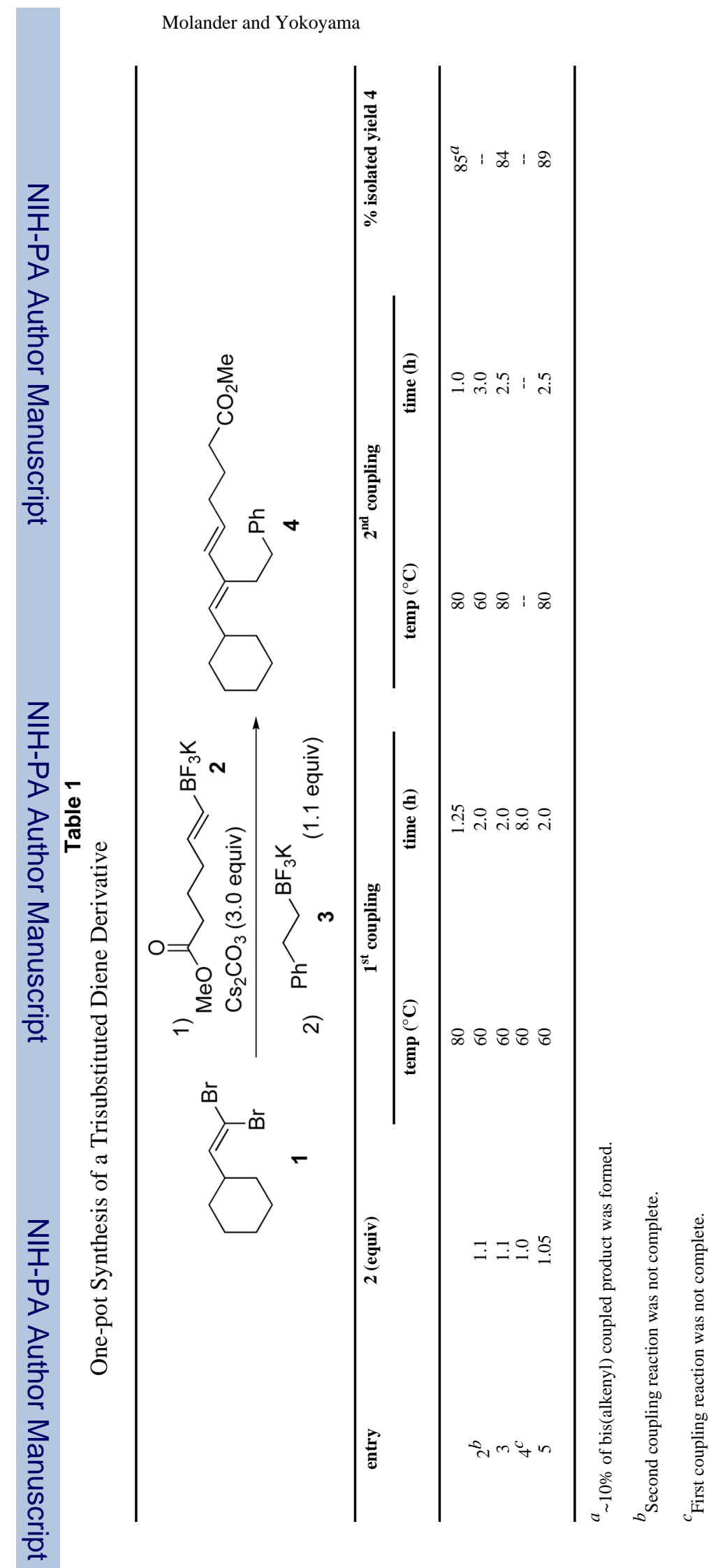

Page 10 


\section{Table 2}

One-pot Reaction of Various Potassium Alkyltrifluoroborates

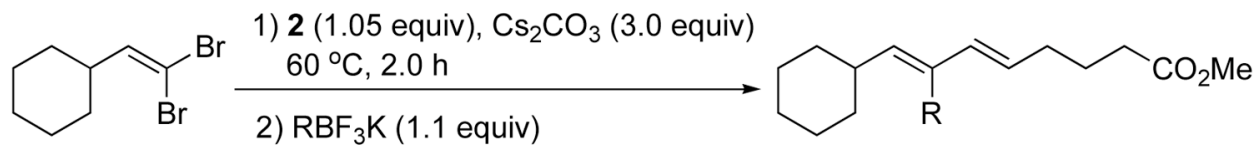

$$
\begin{aligned}
& 1 \quad \mathrm{Cs}_{2} \mathrm{CO}_{3} \text { (3.0 equiv), } 80{ }^{\circ} \mathrm{C} \\
& \text { Toluene/ } \mathrm{H}_{2} \mathrm{O}=3 / 1 \text { to } 3 / 2 \\
& \mathrm{Pd}\left(\mathrm{PPh}_{3}\right)_{4}(7.0 \mathrm{~mol} \%)
\end{aligned}
$$

\begin{tabular}{ccccc}
\hline entry & $\mathbf{R B F}_{3} \mathbf{K}$ & $\mathbf{2}^{\text {nd }}$ coupling time (h) & product & isolated yield (\%) \\
\hline 1 & $\mathrm{PivO}\left(\mathrm{CH}_{2}\right)_{4} \mathrm{BF} \mathrm{F}_{3} \mathrm{~K}(\mathbf{5})$ & 2.0 & $\mathbf{6}$ & 89 \\
2 & $\mathrm{BzO}\left(\mathrm{CH}_{2}\right)_{4} \mathrm{BF}_{3} \mathrm{~K}(\mathbf{7})$ & 2.0 & $\mathbf{8}$ & 90 \\
3 & $\mathrm{NC}_{\left(\mathrm{CH}_{2}\right)_{4} \mathrm{BF}_{3} \mathrm{~K}(\mathbf{9})}$ & 3.0 & $\mathbf{1 0}$ & 89 \\
4 & $\mathrm{CH}_{3} \mathrm{CO}\left(\mathrm{CH}_{2}\right)_{4} \mathrm{BF}_{3} \mathrm{~K}(\mathbf{1 1})$ & 3.0 & $\mathbf{1 2}$ & 89 \\
5 & $\mathrm{PhS}\left(\mathrm{CH}_{2}\right)_{3} \mathrm{BF}_{3} \mathrm{~K}(\mathbf{1 3})$ & 1.5 & $\mathbf{1 4}$ & 90 \\
\hline
\end{tabular}




\section{Table 3}

Reaction of Less Reactive Potassium Alkyltrifluoroborates

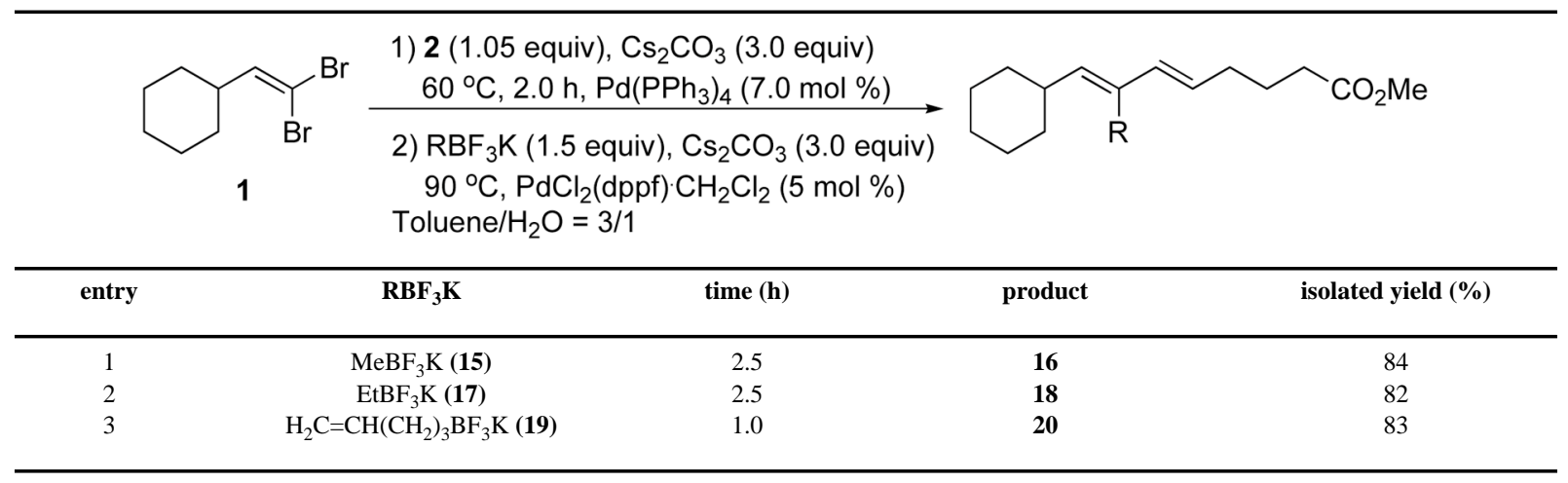




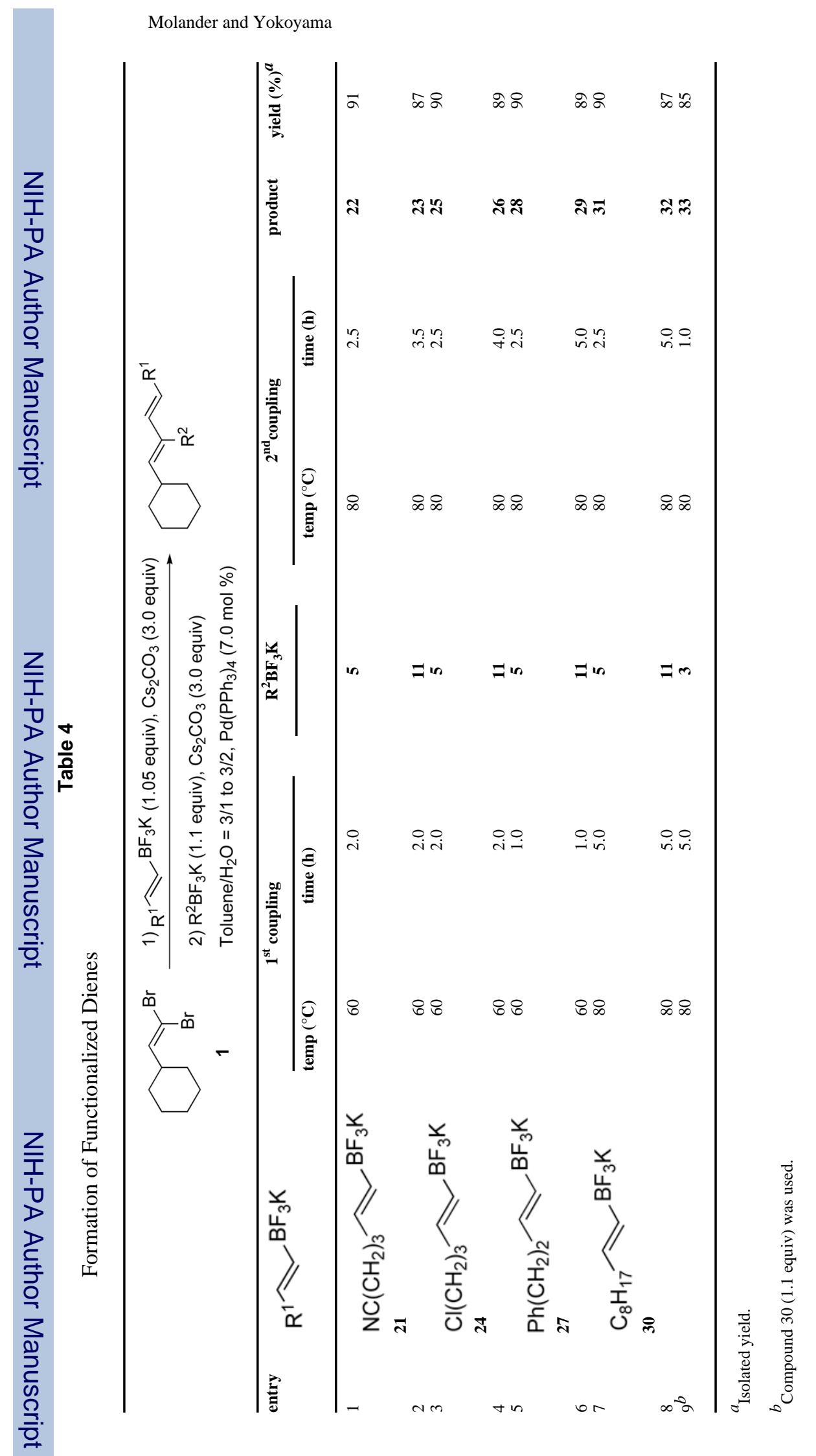

J Org Chem. Author manuscript; available in PMC 2008 September 3. 